\title{
Effective abatement of diesel engine emissions with split injections
}

\author{
Sindhu Ravichettu, G. Amba Prasad Rao and K. Madhu Murthy \\ Department of Mechanical Engineering, NIT, Warangal-506004, India. \\ *E-mail: ambaprasadrao@gmail.com
}

\begin{abstract}
High fuel efficiency with good fuel economy and low carbon monoxide and hydrocarbon emissions are the essential features that are widely used in light, medium and heavy duty applications. However, high emissions of nitrogen (NOx) oxides and particulate matter (PM) is a major challenge and sometimes perplexing. Researchers have tackled the issues on multi-cylinder engines by adopting the common rail fuel injection systems which employs a multiple injection technique. The present work aims at utilising this for a single cylinder diesel engine. To study its efficacy, a numerical analysis by developing a quasidimensional computational model and coupled with thermodynamic considerations to model heat release rates and emissions of NOx and soot. For this purpose, a computer code was developed in $\mathrm{C}^{++}$and validated with the experimental results. Then a split technique was incorporated into the model. It is noted that for a case of 75(8)25 retarded to injection timings of $12 \circ \mathrm{bTDC}, 8 \circ \mathrm{bTDC}$ and $4 \circ \mathrm{bTDC}$ from $16 \circ \mathrm{bTDC}$ has resulted in $23.7 \%, 19.6 \%$ and $16.2 \%$ in soot emissions from the baseline soot emissions. Split injection of 75(8)25 retarded to injection timings of $12 \circ \mathrm{bTDC}, 8 \circ \mathrm{bTDC}$ and $4 \circ \mathrm{bTDC}$ from 16 bTDC has resulted in $34.3 \%, 70.8 \%$ and $76.2 \%$ in NOx emissions from the baseline NOx emissions. With the comparison of conventional techniques of retarded timings and EGR, split strategy was observed to yield better results and it could be emphasised that effective abatement of harmful emissions can be achieved through split injection technique.
\end{abstract}

Key words: Direct injection diesel engine, injection timing, NOx, soot, EGR, split injection

\section{INTRODUCTION}

Diesel engines inherently possess high thermal efficiency, high durability and superior fuel economy as compared to other engines making and thus has made them the most desirable prime movers in heavy, medium and light duty vehicle applications. A higher expansion ratio due to high compression ratios in diesel engines leaves low thermal energy to the exhaust, resulting in low fuel consumption and high power output $[1,2]$. However, diesel engines produce higher levels of nitrogen (NOx) oxides and particulate matter (PM) or soot as compared to their counterpart spark ignition (SI) engines [3-6]. This is due to diesel engines heterogeneous combustion and thus results in a complex unresolved trade-off between NOx and soot emissions [6-9]. To address this issue, many strategies were evolved and adopted over the past two decades in regard to diesel engine research and manufacturing industry. These strategies can be largely categorised as incylinder treatment and exhaust after treatment. Fuel injection parameters play a vital role in diesel engines power control. Suitable after treatment techniques, such as retarded fuel 
injection timings selective catalyst reduction (SCR), are effective in reducing emissions at the exhaust $[10,11]$. Nevertheless, SCR implementation on existing automobiles needs extensive exhaust system modification and results in increased overall cost. Also, in CI engines, the conversion rate of NOx to nitrogen by using an exhaust three-way catalytic converter is quite low as compared to SI engines because of the excess oxygen present in the exhaust stream. In-cylinder treatment strategies include means to investigate combustion modes which differ from the conventional diesel engine combustion to mitigate engine-out emissions without taking a toll on engine performance [12]. New combustion concepts, such as homogenous charge compression ignition (HCCI) and premixed charge compression ignition (PCCI), are also widely explored as they result in simultaneous reduction of NOx and soot emissions by achieving low combustion temperatures aided by intensive premixing of the charge before combustion. However, lack of control over ignition, limited operational range and increased $\mathrm{CO}$ and $\mathrm{HC}$ emissions have made the large scale application of this concept difficult [13].

Exhaust Gas Recirculation (EGR) is one potential pretreatment technique to effectively reduce NOx emissions from diesel engines. However, dilution of charge by using EGR tend to generate more soot emissions, deteriorate fuel consumption along with decrease in engine durability and engine oil quality [14-16]. Advancement of fuel injection timing is predominantly used in diesel engines to increase engine performance and combustion quality. However, this technique increases NOx emissions [14, 17]. Likewise increase in compression ratios (CR), boost pressures and charge intake temperature, etc., have an alternate effect on engine performance and emissions. For the past two decades intensive research were focused on mitigating emissions without affecting engine performance. Therefore researchers were putting efforts to comply the engines with periodic changes in the emission norms. To overcome difficulties with conventional or fossil fuels, studies were done with many gaseous fuels, such as LPG, $\mathrm{CNG}$ etc. Combustion analysis was done and to use $\mathrm{CNG}$ in a direct injection spark injection engine under variable speed operation and was observed to be a better option $[18,19]$. Also, in an attempt to reduce the harmful emissions from diesel fueled engines, researchers have tried to use fuels produced from renewable sources, such as bio-oils. These oils in its neat form are very viscous and were converted to methyl/ethyl esters through transesterification. Such treated oils are popularly called as biodiesel. Few studies were conducted to understand the injected spray behaviour through morphological analysis. The studies in this approach showed higher penetration values for biodiesel fuels due to their viscosity and drops in superficial tension, which facilitate a deeper penetration as compared to those obtained with conventional diesel fuels [20]. As biodiesel fuels need to be produced from bio-resources, it thus requires large amounts of bio-resources. Such biodiesel was blended with petro-diesel by many researchers to obtain benefits of using biodiesel. However, biodiesel fueled engines led to higher emissions of NOx and reduce harmful emissions. The same studies were done by adopting retarded injection timing. Such studies were also predicted through Artificial Neural Network Approach and obtained good predictions [21, 22]. Biodiesel was prepared from different vegetable oils (both edible and non-edible) and was used in both neat and blended form in duel fuel engines. On such study on a duel fuel engine with calophyllum inophyllum oil methyl ester blends and rice husk generated producer gas had resulted in good savings of diesel fuel and confirmed B20 as a better substitute with better performance and low harmful emissions [23]. Furthermore, studies with a non-edible derived biodiesel (Jatropha oil methyl ester) was tried out in DI diesel engine and had noted better performance [24]. Also, studies were availble in literature on numerous vegetable oils and performance and 
emission characteristics were evaluated for three non-edible vegetable oils, such as thumba, jojoba, neem oil, as well as jojoba methyl ester, to study the effect of injection pressure timing [25]. However, looking into the difficulties in renewable fuels availability, efforts were made to effectively utilise diesel fuel while reducing harmful emissions. The performance of compression ignition engines are greatly affected by the amount of fuel injection and fuel injection timing. Hence, the injection system which deals with injection pattern and rate, start of injection, number of pulses in an injection was also observed to play a major role in indictating engine-out emissions along with improvement in engine performance. With the advent of common rail injection system for multicylinder diesel engines the advantages of flexibility in injection pressure, timing, duration, number of injections were realised. The advantages of multiple injections were explored by many researchers to understand their effect on mitigation of engine-out emissions. It was reported in the literature that a multiple injection strategy has the potential to simultaneously reduce $\mathrm{NOx}$ and soot emissions without a great penalty on engine performance [26-31].

Pilot injections, wherein a small amount of fuel is injected before the main injection, with a larger dwell period, was both experimentally and computationally studied by many researchers on diesel engines $[19,32]$. A significant effect on engineout emissions and engine performance was observed with pilot injections. There was a reduction in combustion noise as compared to single injections [33]. Effect of fuel amount injected in each pulse and dwell period between injection pulses was also reported in many studies. Smoke emissions were observed to increase with pilot injections and its trade off increased with combustion noise due to the reduction in premixed phase of combustion. Also, it has revealed an increase in engine stability with increasing injections over a single combustion event $[34,35]$. From the literature it was observed that incylinder techniques had focused on the lowering of NOx emissions and resulted in increasing PM (soot) and vice versa with a consequent effect on engine performance. Split injection strategy adoption was proposed for single cylinder engines which are already available with multi-cylinder engines because such technique would give greater flexibility in engine performance. Therefore, a numerical analysis was done by writing a computer code in $\mathrm{C}^{++}$, to evaluate the performance and emissions of a single cylinder diesel engine with the use of the split-injection technique. For this purpose, thermodynamics-based model was developed with the integration of energy equation for different sub-models to accommodate engine processes. The work was numerically carried out by developing a crank-angle resolved quasi-dimensional computational model coupled with sub-models of heat release rate, NOx and soot formation. Before incorporating the split strategy into model, the model was validated with experimental data and was observed to be in good agreement. This work aims to address the perennial trade-off between NOx, soot and piston work of the engine by using various in-cylinder techniques. A comparative study was carried out between the conventional techniques and proposed technique of split injection to understand the efficacy of the strategies employed.

\section{METHODS AND MATERIALS}

A computer code was written in $\mathrm{C}^{++}$and made use of energy conservation equations to be applied to a closed cycle analysis of typical diesel engine processes. The model took into account the different sub-models that govern/define/estimate main processes in the cylinder from IVC to EVO. A numerical scheme implemented was primarily based on 
the integration of First Law of Thermodynamics and Ideal Gas Equation, coupled with different sub-models, to predict heat transfer losses, chemical composition of combustion species, fuel injection rate, ignition delay, combustion rate, Zeldovich Reaction rates and net soot formed in the engine exhaust.

\section{Energy Conservation Equations for Engine Processes}

In-cylinder temperature and pressure variation at every crank angle step was computed by using the following numerical formulations obtained from the derivations of First Law and Ideal Gas Equation

$$
\begin{gathered}
\frac{d P}{d t}=\frac{A A-\left(\frac{\partial u}{\partial T}\right) \frac{d T}{d t}-\left(\frac{\partial u}{\partial \phi}\right) \frac{d \phi}{d t}}{\left(\frac{\partial u}{\partial P}\right)} \\
\frac{d T}{d t}=\frac{\left(\frac{\partial u}{\partial P}\right)\left[-\rho \frac{\frac{d V}{d t}}{V}+\rho \frac{\frac{d m}{d t}}{m}-\left(\frac{\partial \rho}{\partial \phi}\right) \frac{d \phi}{d t}-A A+\left(\frac{\partial u}{\partial \phi}\right) \frac{d \phi}{d t}\right]}{\left(\frac{\partial u}{\partial P}\right)\left(\frac{\partial \rho}{\partial T}\right)-\left(\frac{\partial \rho}{\partial P}\right)\left(\frac{\partial u}{\partial T}\right)}
\end{gathered}
$$

In Eqs.(1) and (2), $A A, B B$ and $C C$ are given by the following expansions

$$
\begin{array}{r}
A A=-R T \frac{\frac{d V}{d t}}{V}+\frac{1}{m}\left(\dot{Q}+\dot{m}_{i} h_{i}-\dot{m}_{e} h_{e}-\left(u \frac{d m}{d t}\right)_{c v}\right) \\
B B=1-\frac{P}{R}\left(\frac{\partial R}{\partial P}\right) ; C C=1+\frac{T}{R}\left(\frac{\partial R}{\partial T}\right)
\end{array}
$$

\section{Sub-model for Engine Dynamics}

Variation of in-cylinder volume, rate of change of volume, area and stroke are given by the following equations obtained from the derivations of slider crank mechanism [17].

$$
V(\theta)=V_{d}\left[\frac{1}{r_{c}-1}+\frac{1}{2}\left[r+l-\cos \theta-\left(r^{2}-\sin ^{2} \theta\right)^{\frac{1}{2}}\right]\right]
$$

Rate of change of volume with respect to time is given by the following expression,

$$
\frac{d V}{d t}=3 V_{d} N\left[\sin \frac{\pi N}{30} t+\frac{\sin \frac{\pi N}{30} t \cos \frac{\pi N}{30} t}{\left(r^{2}-\sin ^{2} \frac{\pi N}{30} t\right)^{\frac{1}{2}}}\right]
$$

\section{Sub-model for Fuel Injection}

Fuel injection velocity per every working cycle is given by $u_{i n j}=c_{D} \sqrt{2 \Delta P / \rho_{f}}$ and fuel injection rate can be expressed as follows

$$
\dot{m}_{i}=C_{D} A_{n o z} \sqrt{2 \rho_{f} \Delta P}
$$




\section{Sub-model for Ignition Delay}

The present analysis included the sub-model proposed by Hardenberg and Hase [36] to estimate the ignition delay once per engine working cycle. The proposed semi-empirical formula points out the dependence of ignition delay on gas mixture pressure and temperature at the time of fuel injection, equivalence ratio and the fuel ignition quality .

$$
I D(\mathrm{deg})=\left(0.36+0.22 S_{p}\right) \exp \left[E_{a}\left(\frac{1}{R T_{a}}-\frac{1}{17190}\right)+\left(\frac{21.2}{P_{a}-12.4}\right)^{0.63}\right]
$$

It is known that pressure and temperature of the gas mixture vary continuously during ignition delay period because of the on-going compression stroke. In order to accommodate these changing conditions, $t_{i n j}$ was calculated by integrating the reciprocals of instantaneous estimates of ignition delay by using Equation 8 until the following relationship was satisfied,

$$
\int_{t_{i n j}}^{t_{i g n}} \frac{1}{\tau} d t=1
$$

\section{Equations for Heat Release Rate during Combustion}

Diesel engine combustion process in the present work was modelled by using a couple of Wiebe functions to predict heat release rates in pilot, premixed, diffusion and late phases. The general form of Wiebe function to model combustion rate in each phase was given as follows,

$$
R o H R=\sum_{1}^{4}\left[\frac{C_{i}\left(m_{i}+1\right)}{d_{c o m b, i}}\left(\frac{\theta-S O C_{i}}{d_{c o m b, i}}\right)^{m_{i}} e^{\left[-C_{i}\left(\frac{\theta-S O C_{i}}{\left.d_{c o m b i}\right)^{m_{i}+1}}\right]\right.} \cdot \beta_{i}\right]
$$

where $C_{i}$ represents the completeness of combustion in $i$ th phase; $\mathrm{m}_{\mathrm{i}}$ is the parameter that controls the profile of heat release rate of $i$ th phase; $d_{c o m b, i}$ indicates the duration of combustion of $i$ th phase.

\section{Equations for Heat Transfer Model}

Heat transfer losses between the gas mixture and walls of the cylinder was computed by using Newton's Law of Cooling, given by,

$$
Q_{\text {loss }}=A(\theta)_{c y l} \bar{h}_{c}\left(T_{\text {gas }}-T_{\text {wall }}\right)
$$

The present work uses the numerical formulation proposed by Lipkea and DeJoode [37] to compute forced heat transfer coefficient, $\bar{h}_{c}$ and is given by,

$$
\bar{h}_{c}=3.26 D^{\bar{m}-1} P^{\bar{m}} T_{g}^{0.75-1.62 \bar{m}} w^{\bar{m}}
$$

Values for constants in Equation.12, $a$ and $\bar{m}$ were taken as 3.26 and 0.8, respectively. $w$ represents velocity of the burnt gases and according to Lipkea and DeJoode [37] is given by the following expression. $w$ is observed to be dependent on two factors. One is the engine mean piston speed modelled as a function of $\bar{S}_{P}$ and the other is due to swirl motion of the burnt gases generated due to the on-going combustion event and is modelled as a factor of $\left(P-P_{m}\right)$.

$$
w=C_{1} S_{p}+C_{2}\left(T-T_{m}\right)=C_{1} S_{p}+C_{2} \frac{V_{d} T_{g r}}{P_{r} T_{r}}\left(P(\theta)-P_{m}\right)
$$

$P_{r e f}, T_{r e f}$ and $V_{r e f}$ cited in the equation are evaluated at a given reference condition, for example, at IVC condition. 


\section{Equations for Description of Chemistry of Combustion}

In the present analysis, equilibrium composition of the combustion species formed due to the combustion of a general hydrocarbon fuel in the presence of air can be written as follows

$$
\begin{aligned}
& m_{d} \mathrm{C}_{a} \mathrm{H}_{b} \mathrm{O}_{c}+\frac{\left(b+\frac{a}{4}+\frac{c}{2}\right)}{\varphi}\left(O_{2}+3.76 N_{2}\right) \rightarrow \\
& x_{1} \mathrm{H}_{2} \mathrm{O}+x_{2} \mathrm{H}_{2}+x_{3} \mathrm{OH}+x_{4} \mathrm{H}+x_{5} \mathrm{~N}_{2}+x_{6} \mathrm{NO}+x_{7} \mathrm{CO}_{2}+x_{8} \mathrm{CO}+x_{9} \mathrm{O}_{2}+x_{10} \mathrm{O}
\end{aligned}
$$

Equilibrium concentration of combustion species formed was computed by using four atom balance equations obtained by applying mass constraints on $\mathrm{C}-\mathrm{H}-\mathrm{O}-\mathrm{N}$ system and considering six equilibrium equations of combustion.

\section{Nitric Oxide Formation}

A widely adopted scheme proposed by Lavoie et al. [38], which was used for determining NO formation kinetics, was used in the present work. The following chemical reactions were used to explain the formation of NO during the process of combustion,

$$
\mathrm{N}+\mathrm{NO} \leftrightarrow \mathrm{N}_{2}+\mathrm{O} ; \mathrm{N}+\mathrm{O}_{2} \leftrightarrow \mathrm{NO}+\mathrm{O} ; \mathrm{N}+\mathrm{OH} \leftrightarrow \mathrm{NO}+\mathrm{H}
$$

The extended Zeldovich mechanism equation to compute the rate of formation of NO is given as

$$
\frac{d[N O]}{d t}=\frac{2 R_{1}\left\{1-\left([N O] /[N O]_{e}\right)^{2}\right\}}{1+\frac{\left([N O] /[N O]_{e}\right) R_{1}}{\left(R_{2}+R_{3}\right)}}
$$

where $[N O]_{e}$ indicates equilibrium species concentration. $R_{1}, R_{2}$ and $R_{3}$ are given by

$$
R_{1}: k_{1}^{+}[O]_{e}\left[N_{2}\right]_{e} ; R_{2}: k_{2}^{-}[N O]_{e}[O]_{e} ; R_{3}: k_{3}^{-}[N O]_{e}[H]_{e}
$$

Constants used in Eq.17 are defined as follows

$$
k_{1}^{+}=7.6 E 13 \exp (-38000 / T) ; k_{2}^{-}=1.5 E 09 \exp (-19500 / T) ; k_{3}^{-}=2.0 E 14 \exp (-23650 / T)
$$

\section{Sub-model for Soot Formation}

Soot emitted at the exhaust of diesel engines is generally the difference between the soot formed $\left(M_{s f}\right)$ during early combustion stages to the soot consumed or oxidised $\left(M_{s c}\right)$ in the later stages of combustion. Net soot formation rate in the present work was calculated by using model proposed by Lipkea et al. [26]. Soot formation and consumptions rates were estimated by using the following numerical models.

$$
\begin{aligned}
\frac{d m_{s f}}{d t} & =A_{s f} m_{s f}^{0.8} P^{0.5} \exp \left(-E_{s f} / R_{m o l} T\right) \\
\frac{d m_{s c}}{d t} & =A_{s c}\left(P_{O_{2}} / P\right) P^{1.8} \exp \left(-E_{s c} / R_{m o l} T\right)
\end{aligned}
$$

Subscripts $s f$ and $s c$, in the above equations, represent soot formed and consumed, respectively. The values of activation energies (represented by $E_{s f}$ and $E_{s c}$ ) were taken as $82 \times 10^{6}$ and $120 \times 10^{6}$ respectively. $m_{f b}$ represents the mass of fuel burnt at every crank angle step and was determined by using the following expression. 


$$
\frac{d m_{f b}}{d \theta}=\frac{m_{f t} \beta k_{1} k_{2}\left(1-\hat{\theta}^{k_{1}}\right)^{\left(k_{2}-1\right)} \hat{\theta}^{\left(k_{1}-1\right)}+k_{3} k_{4}(1-\beta) \hat{\theta}^{\left(k_{4}-1\right)} \exp \left(-k_{3} \hat{\theta}^{k_{4}}\right)}{\Delta \theta_{\text {comb }}}
$$

where values of coefficients $k_{1}, k_{2}, k_{3}$ and $k_{4}$ are given as [22] $k_{1}=2+$ $1.2510^{-8}\left(\tau_{i d} / N\right)^{2.4}, k_{2}=5000, k_{3}=14.2 / \phi^{0.644}$ and $k_{4}=0.79 k_{3}^{0.25}$

Net soot formation rate was thus expressed as

$$
\frac{d m_{s}}{d t}=\frac{d m_{s f}}{d t}-\frac{d m_{s c}}{d t}
$$

Performance and emission characteristics prediction of a compression ignition direct injection engine was carried out by sequential evaluation of the following events: mass of gas mixture (air + EGR, if any) entrained into the combustion chamber at IVC condition, thermophysical properties of the working fluid, heat transfer losses, rate of fuel injection, ignition lag, combustion rates in different phases and $\mathrm{NO}$ and soot formation. The model uses the mathematical relationships detailed in the preceding paragraphs to calculate the parameters involved.

\section{Validation of The Model}

The developed model was validated for its in-cylinder pressure history, NO and soot emissions with two sets of experimental data. One set of data was obtained from the experimental engine installed at authors' institute and the other from literature Rakopoulos et al. [28]. Engine at hand was a fully automated single cylinder, four-stroke, water cooled experimental engine, coupled with "Kirloskar" dynamometer with load absorbing facility installed at authors' institute. Geometrical and operational specifications of the engine are listed in Table 1. Figure1a shows the comparison between in-cylinder pressures obtained from the simulation model and experimental data at part load operation for the engine operating at a speed of $1500 \mathrm{rpm}$ at an injection timing of $23^{\circ} \mathrm{bTDC}$. Figure1(b) depicts the comparison between in-cylinder pressure traces obtained from the simulation model and experimental data, as reported by Rakopoulos et al. [39]. A good concurrence between predicted and experimental data can be observed from Figure1a and Figure 1(b), thus validating the model and its implementation. A comparison between peak combustion pressures of predicted and experimental data at varied injection timings and increasing loads is shown in Figure2(a). Figure2(b) compares the predicted and experimental cumulative NO and soot levels with increasing loads. The rise in NO and soot emission levels with increase in load was expected due to increase in combustion temperatures at stoichiometric conditions of fuel and air.

Table 1. Specifications of a single cylinder "Kirloskar" engine.

\begin{tabular}{llc}
\hline Parameter & Value & Unit \\
\hline Cylinder bore X Stroke & $0.08 \times 0.110$ & $\mathrm{~m}$ \\
Compression ratio & $16.5: 1$ & - \\
Connecting rod length & 0.022 & $\mathrm{~m}$ \\
Engine speed & 1500 & $\mathrm{rpm}$ \\
Static injection timing & 23 & ${ }^{\circ} \mathrm{CA}$ bTDC \\
IVO; IVC & $4.5^{\circ} \mathrm{aTDC} ; 35.5^{\circ} \mathrm{aBDC}$ & ${ }^{\circ} \mathrm{CA}$ \\
EVO; EVC & $35.5^{\circ} \mathrm{bBDC} ; 4.5^{\circ} \mathrm{aTDC}$ & ${ }^{\circ} \mathrm{CA}$ \\
\hline
\end{tabular}


In this section a comparison was made between the values obtained from the theoretical model and the measured experimental values, so that the model could be tested for its performance and emissions. The model was validated with experimental investigations in the authors' laboratory. Validation tests were conducted for in-cylinder pressures, NO and soot emission formations in the cylinder for different engine geometrical and operating conditions.

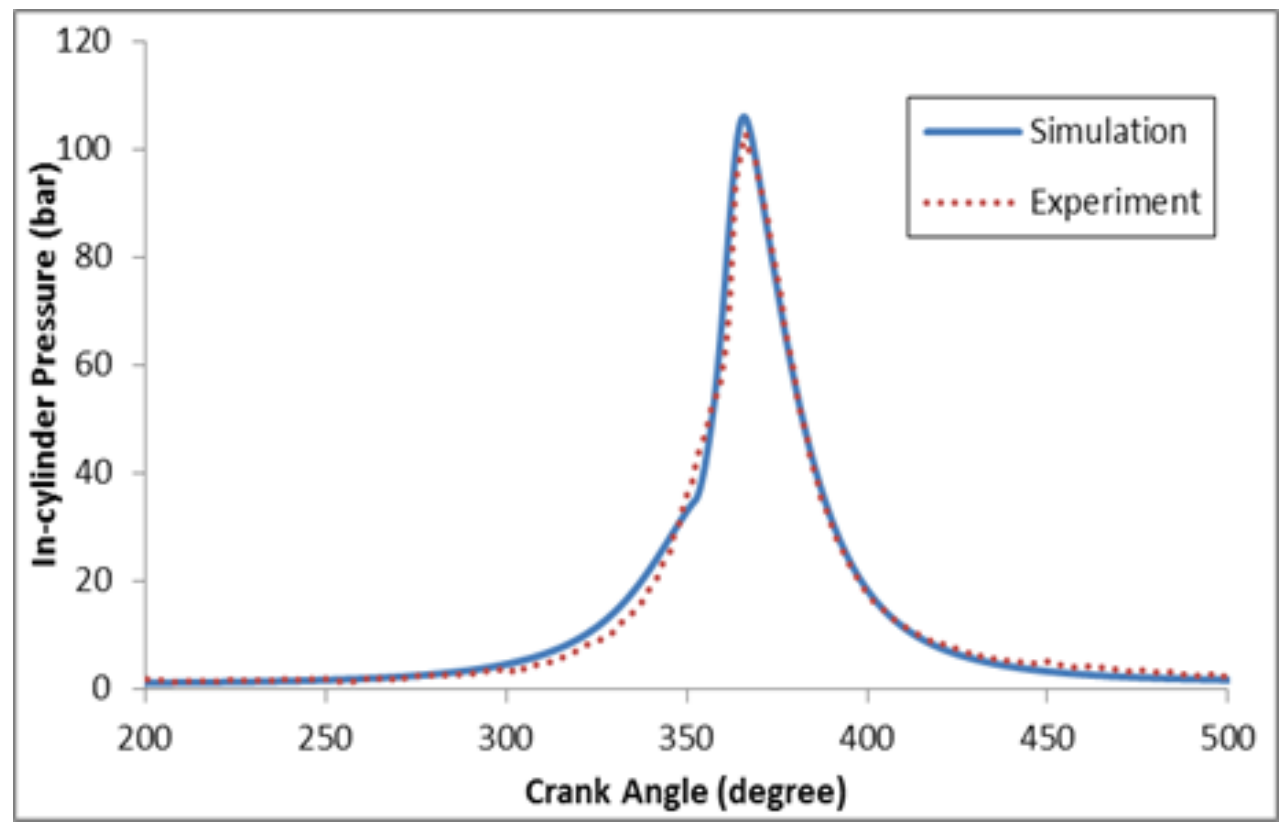

(a)

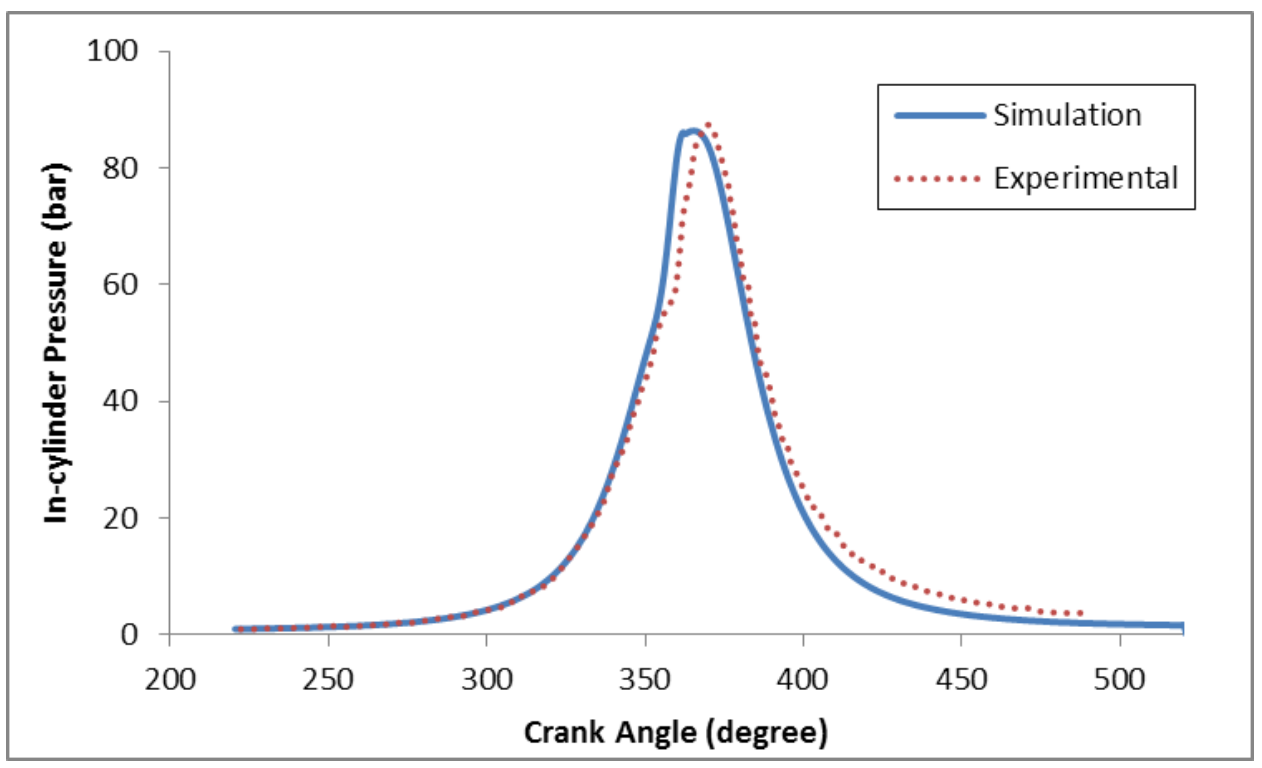

(b)

Figure 1: (a) Comparison between measured and predicted values for engine operating at $1500 \mathrm{rpm}$, at an injection timing of 23_bTDC at 25\% load (b) Calculated and experimental values of nitric oxide (NO) concentration and soot density with increasing load (expressed as IMEP) at $2500 \mathrm{rpm}$ and at an injection timing of $20^{\circ} \mathrm{bTDC}$ [21]. 


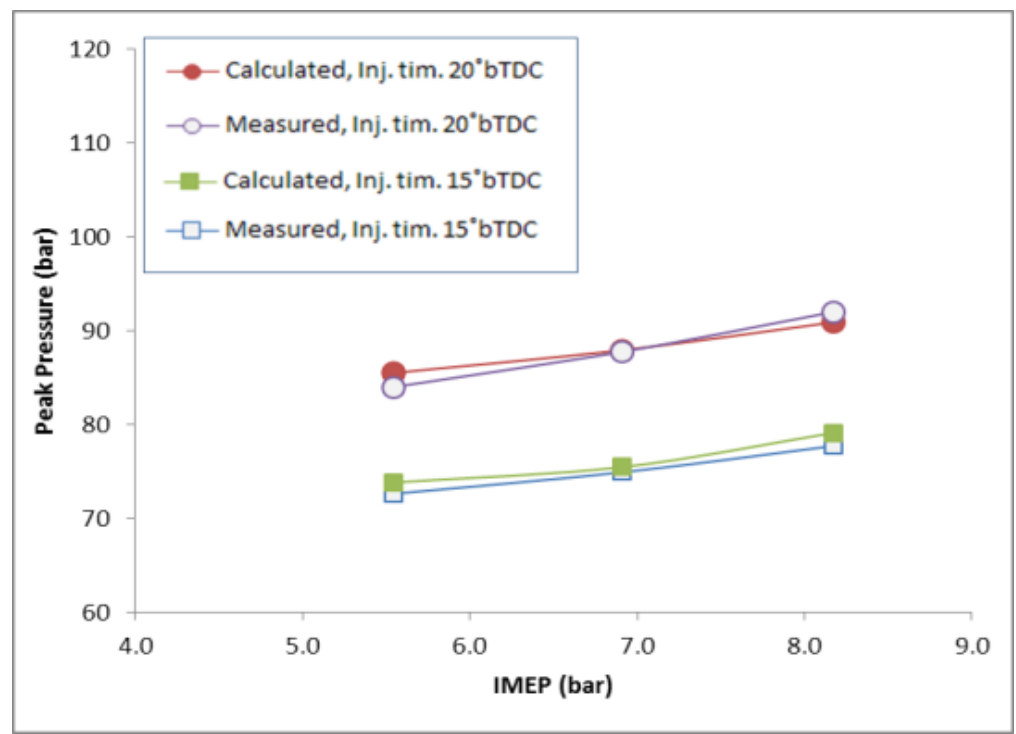

(a)

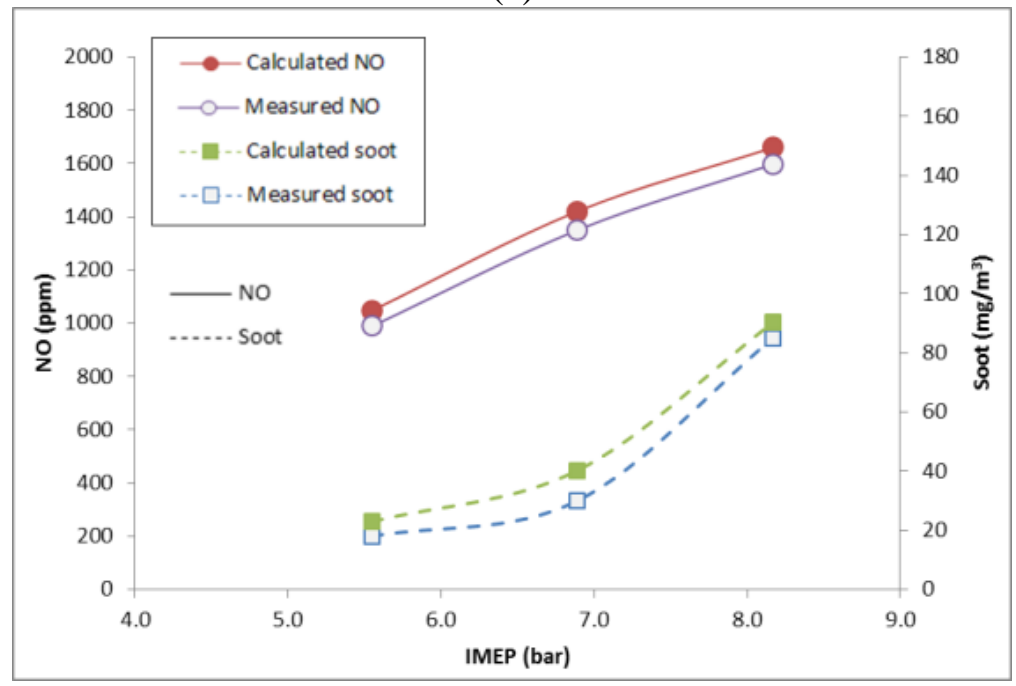

(b)

Figure 2. (a) Calculated and predicted values of peak combustion pressures with increasing loads (expressed as IMEP) at $2500 \mathrm{rpm}$ and at an injection timing of $20^{\circ} \mathrm{bTDC}$ and $15^{\circ}$ bTDC [39]; (b) Calculated and experimental values of nitric oxide (NO) concentration and soot density with increasing load (expressed as IMEP) at $2500 \mathrm{rpm}$ and at an injection timing of $20^{\circ} \mathrm{bTDC}$ [39].

\section{RESULTS AND DISCUSSION}

In the present numerical study emphasis was given to study the effect of split or multiple injection strategy and the results was compared with convention techniques to show the efficacy of split strategy on NO-soot emissions.

\section{Studies on Effect of Split Injection}

The effect of split injection strategy was incorporated in the developed phenomenological combustion model to study engine performance and emissions. In the proposed method, conventional single fuel injection was divided into two injections over a single combustion event. Figure 5 illustrates the heat release rate patterns of split and single injections for the same injection timing $\left(16^{\circ} \mathrm{bTDC}\right)$ and for the same fuel injected amount. 
SOI1 and SOI2 represented the start of first and second injection pulses, respectively. From the figure it can be derived that split injection reduces the overall premixed phase of combustion and enhances diffusion phase of combustion as compared to single injection. It can be said here that, in split injection, a lower amount of fuel was injected in the first pulse (around 10\%-25\% of the total amount of fuel) whereas $100 \%$ of fuel was injected in the case of single injection. With single injection, a major portion of fuel was burnt in premixed phase of combustion, whereas, in split injection, the first part of fuel would give rise to high temperatures with relatively lower than the single injection case. The remaining fuel was later injected with a certain injection pause (or dwell period) after the initial injection. The combustion of fuel from the initial pulse created a conducive environment for the later injected fuel. This reduced the ignition delay of second pulse of fuel making the combustion predominantly mixed-controlled. This restrained the peak heat release rate and delayed a major portion of combustion shifting the combustion event away from TDC, as shown in Figure 5.

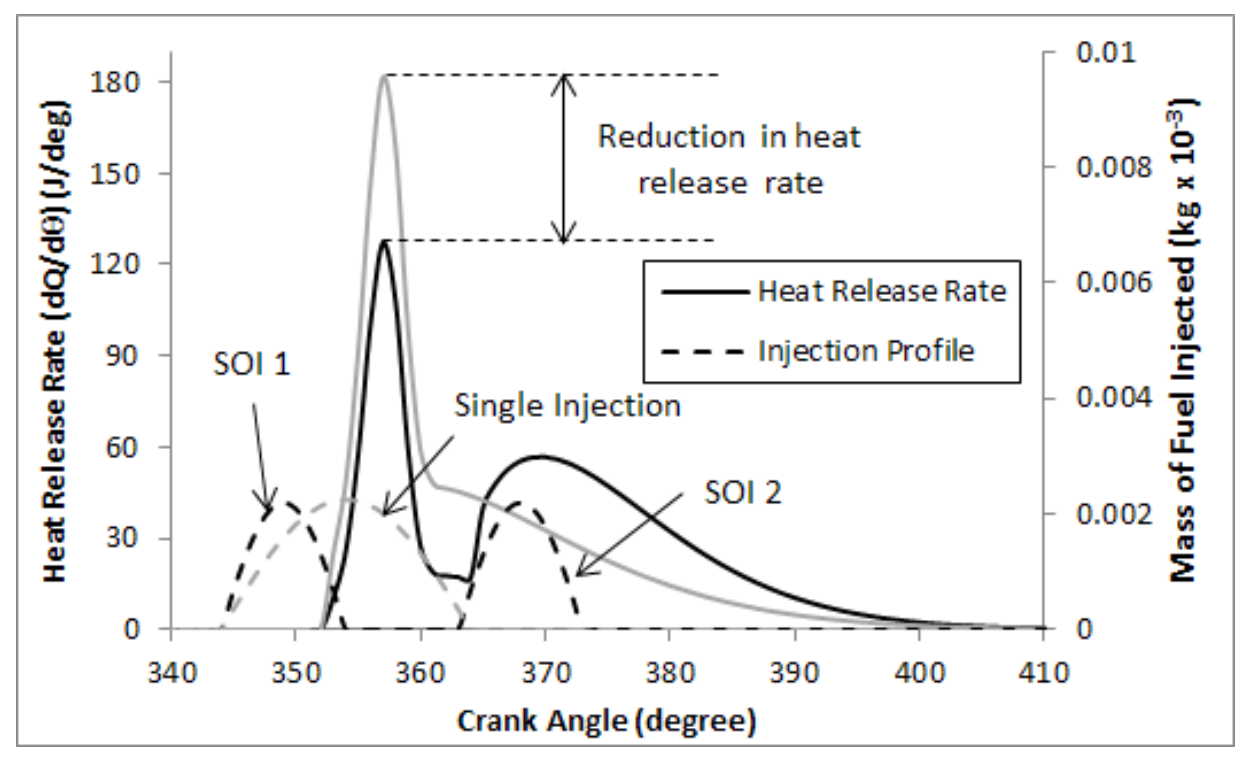

Figure 5. Comparison of heat release rate patterns for single and split injections.

To further explore the benefits of split injection strategy, few injection schemes were designed and implemented. The schematic of injection schemes is shown in Figure 12. Injection schemes consisted of one single injection $\left(16^{\circ} \mathrm{bTDC}\right)$ and two split injections. The amount of fuel injected in the first pulse in split injections was increased from $25 \%$ to $75 \%$ and was proportionally reduced in the second injection $(75 \%$ and $25 \%$, respectively). Dwell period (or injection pause) in split injection cases was kept constant for the present analysis at $8^{\circ}$ of CA. In the present work, a split injection strategy was represented in the following pattern. Percentage of fuel injected in the first pulse/percentage of fuel injected in the second pulse. For example, 25/75 represented 25\% of fuel injected in first and remaining $75 \%$ of fuel was injected in second pulse. The injection timing of all the designed schemes was taken as $16^{\circ} \mathrm{bTDC}$. Fuel injected in all the strategies was taken as constant $(36.84 \mathrm{mg} / \mathrm{cycle})$. The duration of fuel injection for all the cases was considered to be $20^{\circ} \mathrm{CA}$. In split injection cases, the injection duration of each pulse varied according to the amount of fuel injected in that pulse, as shown in Figure 6. 


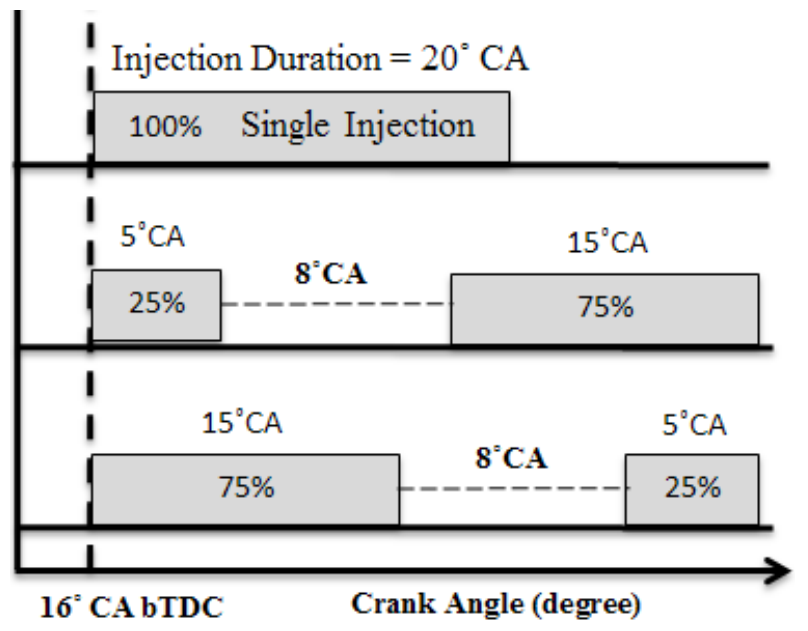

Figure 6. Schematic of designed injection strategies.

Figure 7 represents heat release rate profiles of split injection strategies as compared to a single injection strategy $\left(16^{\circ} \mathrm{bTDC}\right)$. The injection profile of split strategy is also shown in Figure 7. In-cylinder temperatures of split injection strategies were shown against single injection pressure profile.

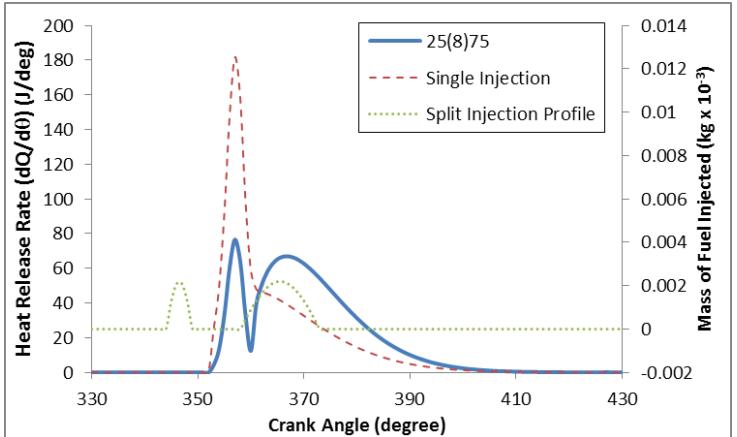

(a)

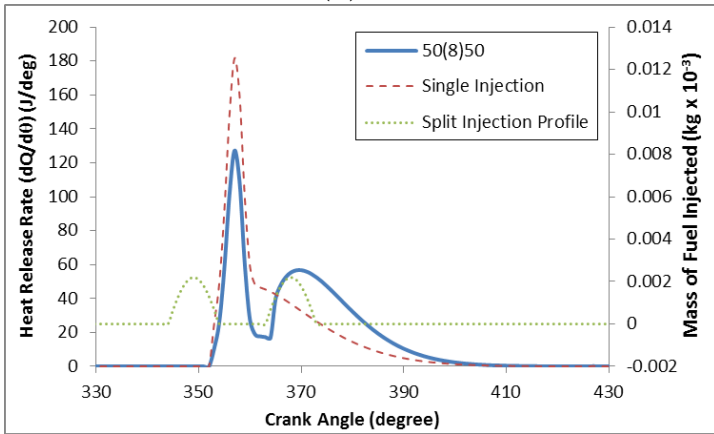

(c)

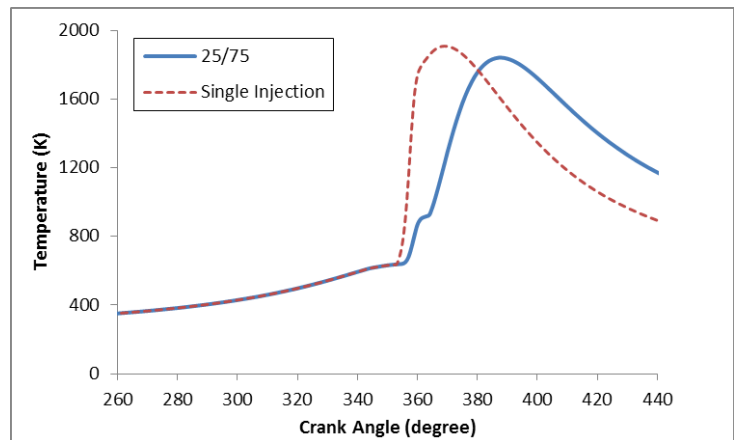

(b)

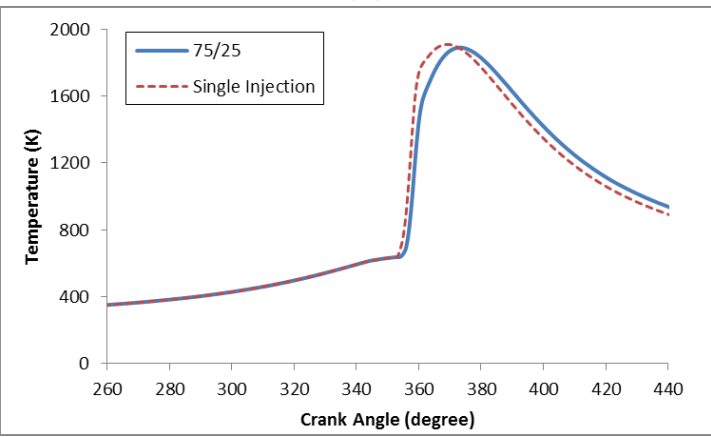

(d)

Figure 7. Heat release rate and temperature prediction for split injections. Injection pause between the two pulses was $8{ }^{\circ} \mathrm{CA}$.

From Figure 7, it can be understood that as the amount of fuel injected in the first pulse increases, premixed phase of combustion increases. When major quantity of fuel ( $75 \%$ of fuel) was injected in the second pulse, combustion becomes predominantly mixed-controlled with only a lower amount of fuel (less than $25 \%$ ) participated in the premixed combustion. In such a case $(25 / 75)$, major portion of combustion was delayed 
by a period of dwell $\left(8^{\circ} \mathrm{CA}\right)$ shifting the combustion event away from TDC. However, when a major quantity of fuel (75\% of fuel) was injected in the first pulse $(75 / 25)$, heat release rate profile became similar to that of single injection case with the same injection timing. In-cylinder temperatures also increased with increase in fuel injected in first pulse. Hence, with 25/75 scheme, there was a shift in peak in-cylinder temperature away from TDC, depicting energy was released more into the power stroke. Also, as the fuel injected in the first pulse increased, temperature profile became more similar to single injection case. Hence early combustion increased with increased amount of fuel injected in first pulse.

\section{Emissions for a Constant Dwell Period of $8^{\circ} \mathrm{CA}$}

Figure 8 shows NO and soot formation rates for different injection schemes $(1$ single injection and 2 split injections) as a function of crank angle. It can be observed from the figure that split injections had a significant effect on engine-out emissions. From Figure 9 , it can be derived that both the split injection schemes had either significantly or marginally reduced $\mathrm{NO}$ emissions from single injection case. However, 25/75 injection scheme has increased soot emissions from baseline (single injection) and 75/25 had decreased soot emissions.

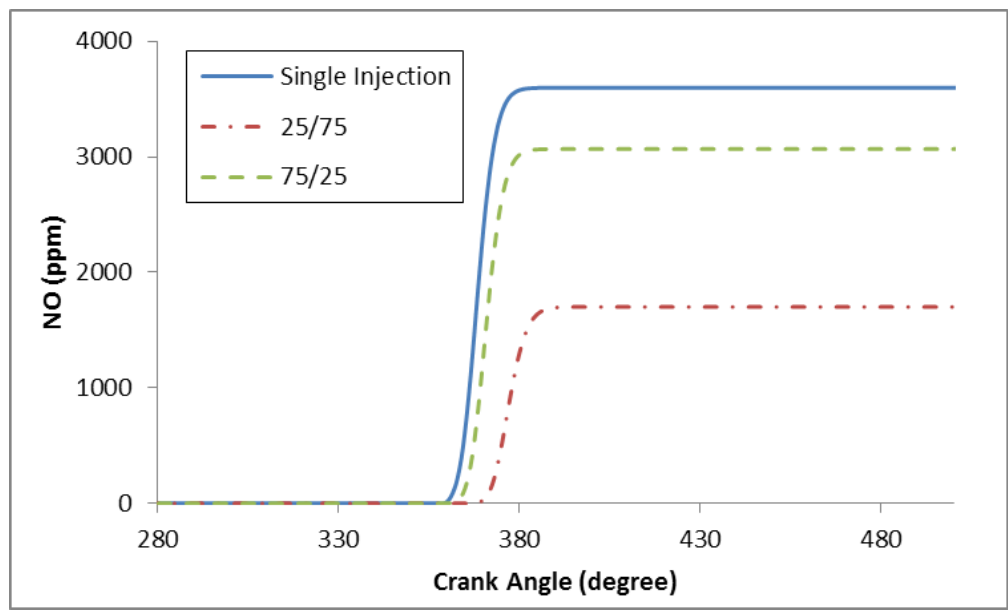

(a)

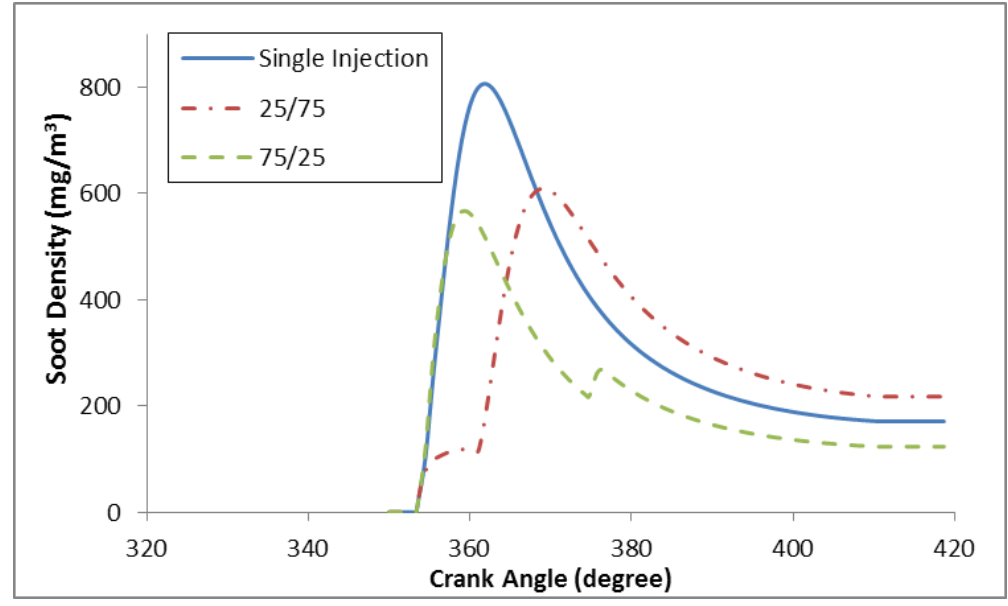

(b)

Figure 8. Predicted NO and soot formation histories as a function of crank angle for different injection strategies. 
From the figure it can be observed that as the fuel was injected in the first pulse decreased from $100 \%$ to $75 \%$ and $25 \%$, NO emissions were also reduced. From the figure it can be seen that single injection had triggered the highest premixed combustion phase, followed by $75 / 25$ and $25 / 75$. As the amount of fuel participated in the premixed phase of combustion increased, the peak in-cylinder temperatures also increased. Also, as the amount of fuel injected in the first pulse increased, resident time of burnt charge at high combustion temperatures increased, thus increasing the tendency of NO formation. In the case of 25/75, major combustion event was delayed or retarded by a period of dwell angle, which made it acted as a retarded combustion. Enhanced diffusion phase of combustion and lower peak in-cylinder temperature suppressed NO formation tendencies. With 75/25 case, NO emissions were similar to that of single injection case. This can be reasoned with the similar heat release rate of $75 / 25$ as that of single injection. Hence from the computations it can be derived that $25 / 75$ scheme acts more as a retarded injection by delaying major portion of combustion. This restrains the NO formation rates due to reduced premixed phase of combustion. However, 75/25 scheme generated similar NO emissions as that of single injection case as a major portion of fuel is combusted in early stages of combustion. Regarding soot emissions, with 75/25 injection scheme, $75 \%$ of fuel injected in the first pulse created a hot conducive environment for oncoming second injection. The initial peak of soot formation was reduced (as compared to single injection) since only $75 \%$ of fuel was injected in the first pulse. And the subsequent injection of a lower amount of fuel (25\%) was injected into a relatively higher pressure and temperature environment. Hence the later injected fuel got rapidly consumed and combusted, leaving almost no probability of unburnt fuel in the combustion chamber. In the case of 25/75 scheme, enhanced diffusion combustion phase increased the tendency of soot formation. Also, during second injection, relatively rich mixture was present, favouring soot formation. To overview the effect of split injections on engine-out emissions, particularly of NO and soot, the cumulative values of NO and soot were plotted as shown in Figure 9. From the figure it can be observed that split injections had moved the NO-soot tradeoff to a lower level of $\mathrm{NO}$ emissions for both the injection schemes and lower level of soot emissions for $75 / 25$ injection scheme.

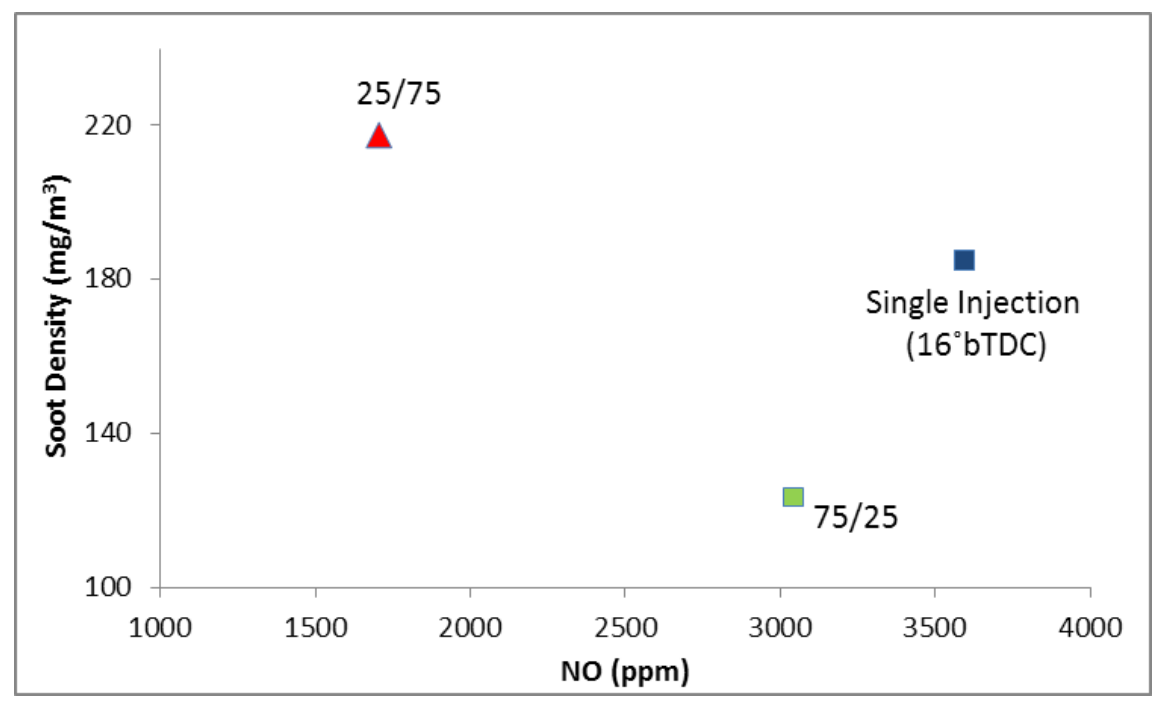

Figure 9. Predicted NO-soot trade-off for the designed injection strategies. 


\section{Comparison of NO Reduction Techniques}

From the numerical results presented, it can also be observed that (single) retarded injection with SOI at $8^{\circ}$ bTDC, EGR of $20 \%$ and split injection of $25 / 75$ had resulted in almost similar levels of NO emissions, as shown in Figure 11. It can also be observed that with EGR-20\%, the formation of NO had started much earlier than the other two techniques.

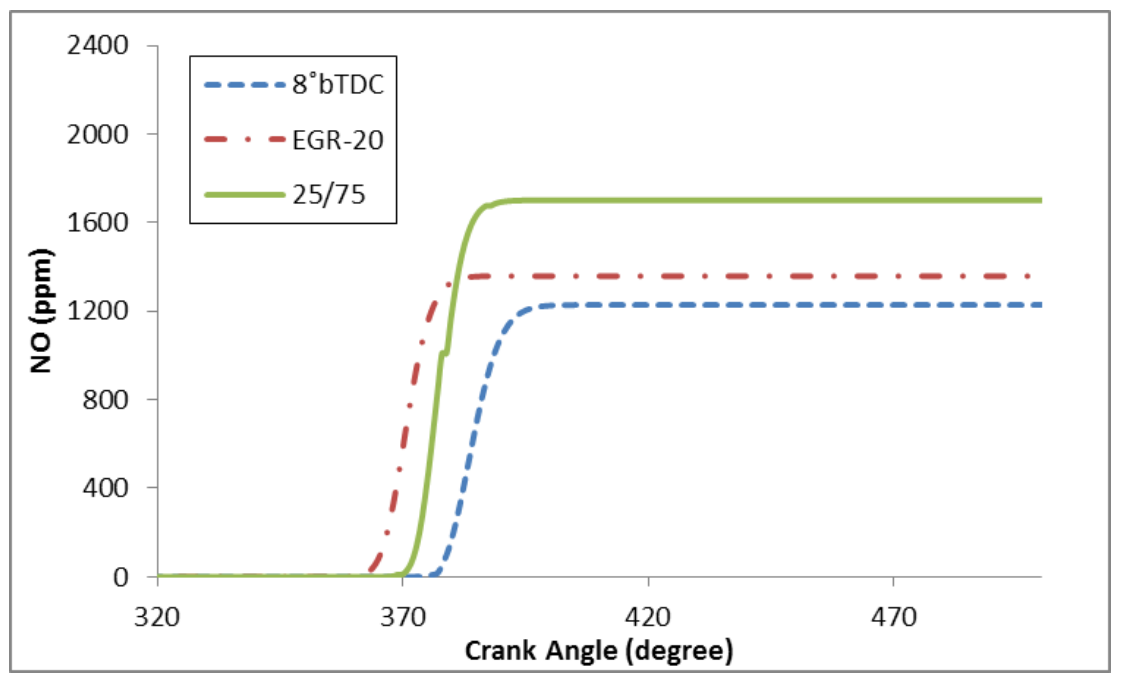

Figure 10. Comparison of NO formation rates.

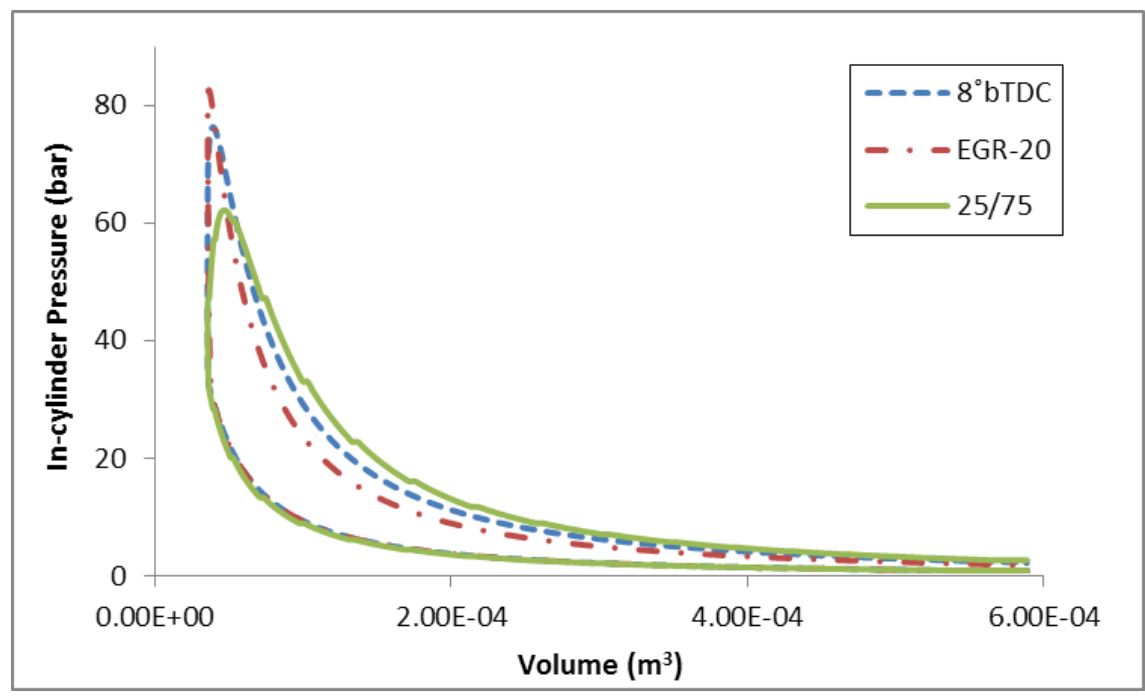

Figure 11. Comparison of P-V diagrams (or indicator diagrams).

A comparison of P-V diagrams (or indicator diagrams) was shown in Figure 11. It can be observed that peak pressures obtained in the case of $25 / 75$ was reduced as compared to other two cases of single injection; there was an overall increase in pressure during power stroke. From the figures, it can be thus derived that for the same NO emission levels of single injections ( $8^{\circ} \mathrm{bTDC}$ and EGR-20\%) and split injection (25/75), split injection was observed to reduce NO emission levels without a great penalty on engine performance. 


\section{CONCLUSIONS}

An attempt was made, by using a numerical analysis, to employ split injection strategy in single cylinder diesel engines. A computational model was successfully developed to predict the engine performance and emissions by using conventional and advanced techniques. The model was observed to be insensitive of engine geometry and its operating conditions. It is observed that split injection strategy was to be a promising technique in addressing piston work, NOx and soot emission trade-off. It was noted that

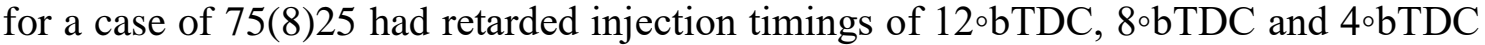
from $16{ }^{\circ}$ bTDC had resulted in $23.7 \%, 19.6 \%$ and $16.2 \%$ in soot emissions from baseline soot emissions. Split injection of 75(8)25 had retarded to injection timings of $12 \circ \mathrm{bTDC}$, $8 \circ \mathrm{bTDC}$ and $4 \circ \mathrm{bTDC}$ from $16{ }^{\circ} \mathrm{bTDC}$ had resulted in $34.3 \%, 70.8 \%$ and $76.2 \%$ in NOx emissions from baseline NOx emissions. With the comparison of conventional techniques of retarded timings and EGR, split was observed to yield better results and it can be emphasised that effective abatement harmful emissions can be achieved through split injection technique. It is recommended to develop an electronic gadget that facilitates automatic control of split fuel injection strategy experimentally.

\section{ACKNOWLEDGEMENTS}

The work is done at the facilities available with the Department of Mechanical Engineering of the Institute. The authors are grateful the National Institute of Technology, Warangal for providing all facilities to carry out the present work.

\section{REFERENCES}

[1] Borman GL, Ragland KW. Combustion engineering: McGraw-Hill Science/Engineering/Math; 1998.

[2] Ramasamy D, Goh C, Kadirgama K, Benedict F, Noor M, Najafi G, et al. Engine performance, exhaust emission and combustion analysis of a 4-stroke spark ignited engine using dual fuel injection. Fuel. 2017;207:719-28.

[3] Heywood JB. Internal combustion engine fundamentals: Mcgraw-hill New York; 1988.

[4] Mohd Noor CW, Mamat R, Najafi G, Mat Yasin MH, Ihsan CK, Noor MM. Prediction of marine diesel engine performance by using artificial neural network model. Journal of Mechanical Engineering and Sciences. 2016;10:1917-30.

[5] Kettner M, Dechent S, Hofmann M, Huber E, Arruga H, Mamat R, et al. Investigating the influence of water injection on the emissions of a diesel engine. Journal of Mechanical Engineering and Sciences. 2016;10:1863-81.

[6] Ibrahim F, Wan Mahmood WMF, Abdullah S, Abu Mansor MR. Numerical investigation of soot mass concentration in compression ignition diesel engine. Journal of Mechanical Engineering and Sciences. 2016;10:2275-87.

[7] Samantaray BB, Mohanta CK. Analysis of industrial flame characteristics and constancy study using image processing technique. Journal of Mechanical Engineering and Sciences. 2015;9:1604-13.

[8] Nayak SK, Mishra PC. Emission from a dual fuel operated diesel engine fuelled with calophyllum inophyllum biodiesel and producer gas. International Journal of Automotive and Mechanical Engineering. 2017;14:3954-69. 
[9] Hasan MM, Rahman MM, Kadirgama K. A review on homogeneous charge compression ignition engine performance using biodiesel-diesel blend as a fuel. International Journal of Automotive and Mechanical Engineering. 2015;11:2199211.

[10] Pundir B. Engine emissions: Pollutant formation and advances in control technology: Alpha Science International, Limited; 2007.

[11] Ramasamy D, Zainal Z, Kadirgama K, Briggs HW-G. Effect of dissimilar valve lift on a bi-fuel cng engine operation. Energy. 2016;112:509-19.

[12] Ferguson CR, Kirkpatrick AT. Internal combustion engines: Applied thermosciences: John Wiley \& Sons; 2015.

[13] Gan S, Ng HK, Pang KM. Homogeneous charge compression ignition (hcci) combustion: Implementation and effects on pollutants in direct injection diesel engines. Applied energy. 2011;88:559-67.

[14] Zeng K, Huang Z, Liu B, Liu L, Jiang D, Ren Y, et al. Combustion characteristics of a direct-injection natural gas engine under various fuel injection timings. Applied Thermal Engineering. 2006;26:806-13.

[15] Agarwal D, Singh SK, Agarwal AK. Effect of exhaust gas recirculation (egr) on performance, emissions, deposits and durability of a constant speed compression ignition engine. Applied energy. 2011;88:2900-7.

[16] Ramasamy D, Aik Soon K, Walker-Gitano Briggs H, Zainal ZA. Variation of airflow pattern through dissimilar valve lift in a spark ignition engine. Journal of the Chinese Institute of Engineers. 2013;36:1083-96.

[17] Kouremenos D, Hountalas D, Binder K, Raab A, Schnabel M. Using advanced injection timing and egr to improve di diesel engine efficiency at acceptable no and soot levels. SAE Technical Paper; 2001.

[18] Aziz ARA, Shahzad R. Combustion analysis of a cng direct injection spark ignition engine. International Journal of Automotive and Mechanical Engineering. 2010;2:157-70.

[19] Ramasamy D, Kadirgama K, Rahman M, Zainal Z. Analysis of compressed natural gas burn rate and flame propagation on a sub-compact vehicle engine. International Journal of Automotive \& Mechanical Engineering. 2015; 11:240516.

[20] Visconti P, Primiceri P, Strafella L, Carlucci A, Ficarella A. Morphological analysis of injected sprays of different bio-diesel fuels by using a common rail setup controlled by a programmable electronic system. International Journal of Automotive \& Mechanical Engineering. 2017; 14:3849-71.

[21] Rostami S, Ghobadian B, Kiani MKD. Effect of the injection timing on the performance of a diesel engine using diesel-biodiesel blends. International Journal of Automotive and Mechanical Engineering. 2014;10:1945-58.

[22] Shukri MR, Rahman M, Ramasamy D, Kadirgama K. Artificial neural network optimization modeling on engine performance of diesel engine using biodiesel fuel. International Journal of Automotive and Mechanical Engineering. 2015;11:2332-47.

[23] Nayak S, Mishra P. Emission from a dual fuel operated diesel engine fuelled with calophyllum inophyllum biodiesel and producer gas. International Journal of Automotive and Mechanical Engineering. 2017; 14:3954-69.

[24] Nayak C, Pattanaik BP, Nayak SK. Effect of preheated jatropha oil and jatropha oil methyl ester with producer gas on diesel engine performance. International Journal of Automotive and Mechanical Engineering. 2014;9:1709-22. 
[25] Radha KK, Sarada SN, Rajagopal K, Nagesh E. Performance and emission characteristics of ci engine operated on vegetable oils as alternate fuels. International Journal of Automotive and Mechanical Engineering. 2011;4:414-27.

[26] Li J, Chae JO, Lee S, Jeong J. Modeling the effects of split injection scheme on soot and no emissions of direct injection diesel engines by a phenomenological combustion model. SAE Technical Paper; 1996.

[27] Mendez S, Thirouard B. Using multiple injection strategies in diesel combustion: Potential to improve emissions, noise and fuel economy trade-off in low $\mathrm{cr}$ engines. SAE International Journal of Fuels and Lubricants. 2008;1:662-74.

[28] Badami M, Mallamo F, Millo F, Rossi E. Influence of multiple injection strategies on emissions, combustion noise and BSFC of a DI common rail diesel engine. SAE Technical Paper; 2002.

[29] Husberg T, Denbratt I, Karlsson A. Analysis of advanced multiple injection strategies in a heavy-duty diesel engine using optical measurements and CFDsimulations. SAE Technical paper; 2008.

[30] Shundoh S, Komori M, Tsujimura K, Kobayashi S. Nox reduction from diesel combustion using pilot injection with high pressure fuel injection. SAE Technical Paper; 1992.

[31] Mobasheri R, Peng Z, Mirsalim SM. Cfd evaluation of effects of split injection on combustion and emissions in a di diesel engine. SAE Technical Paper; 2011.

[32] Tow T, Pierpont D, Reitz RD. Reducing particulate and $\mathrm{No}_{\mathrm{x}}$ emissions by using multiple injections in a heavy duty DI diesel engine. SAE Technical Paper; 1994.

[33] Carlucci P, Ficarella A, Laforgia D. Pilot injection behavior and its effects on combustion in a common rail diesel engine. Department of Engineering. For Innovation, Research Center for Energy and. Environment (CREA), ITALY; 2001.

[34] Nishimura T, Satoh K, Takahashi S, Yokota K. Effects of fuel injection rate on combustion and emission in a di diesel engine. SAE Technical Paper; 1998.

[35] Payri F, Broatch A, Salavert J, Martín J. Investigation of diesel combustion using multiple injection strategies for idling after cold start of passenger-car engines. Experimental Thermal and Fluid Science. 2010;34:857-65.

[36] Hardenberg H, Hase F. An empirical formula for computing the pressure rise delay of a fuel from its cetane number and from the relevant parameters of directinjection diesel engines. SAE Technical Paper; 1979.

[37] Lipkea WH, DeJoode AD. Direct injection diesel engine soot modeling: Formulation and results. SAE Technical Paper; 1994.

[38] Lavoie GA, Heywood JB, Keck JC. Experimental and theoretical study of nitric oxide formation in internal combustion engines. Combustion Science and Technology. 1970;1:313-26.

[39] Rakopoulos C, Rakopoulos D, Giakoumis E, Kyritsis D. Validation and sensitivity analysis of a two zone diesel engine model for combustion and emissions prediction. Energy Conversion and Management. 2004;45:1471-95.

\section{NOMENCLATURE}

\section{Notation}

$\mathrm{D}$

$\mathrm{m}$

$\mathrm{N}$
Bore $(\mathrm{m})$

Mass (kg)

Engine speed (rpm)
Abbreviations

TDC Top dead centre

BDC Bottom dead centre

IVO/IVC Inlet valve opening/closing 


\begin{tabular}{|c|c|c|c|}
\hline $\mathrm{P}$ & Pressure $(\mathrm{Pa})$ & EVO/EVC & $\begin{array}{l}\text { Exhaust } \\
\text { opening/closing }\end{array}$ \\
\hline Q & Heat (J) & & \\
\hline $\mathrm{r}$ & Crank radius (m) & Subscripts & \\
\hline $\mathrm{R}_{\mathrm{mol}}$ & $\begin{array}{l}\text { Universal gas constant } \\
(8314.3 \mathrm{~J} / \mathrm{kmol} \mathrm{K})\end{array}$ & $\mathrm{f}$ & Fuel \\
\hline $\mathrm{T}$ & Temperature $(\mathrm{K})$ & $\mathrm{c}$ & Convection \\
\hline $\mathrm{u}$ & Internal energy $(\mathrm{J})$ & comb & Combustion \\
\hline $\mathrm{V}$ & Instantaneous volume & cyl & Cylinder \\
\hline $\mathrm{d}()$ & $\begin{array}{l}\text { Ordinary derivate preceding } \\
\text { term }\end{array}$ & $\mathrm{fb}$ & Fuel burnt \\
\hline \multirow{2}{*}{\multicolumn{2}{|c|}{ Greek Symbols }} & ign & Ignition \\
\hline & & inj & Injection \\
\hline$\phi$ & $\begin{array}{l}\text { Equivalence ratio (or mixture } \\
\text { richness) }\end{array}$ & $\mathrm{m}$ & Motoring \\
\hline$\rho$ & Density $\left(\mathrm{kg} / \mathrm{m}^{3}\right)$ & ref & Reference condition \\
\hline$\beta$ & Fuel mass fraction burnt & $\mathrm{sf} / \mathrm{sc}$ & Soot formed/consumed \\
\hline
\end{tabular}

